\title{
PENGANTAR PENDIDIKAN AGAMA HINDU
}

\section{KETUT SUDARSANA}

\section{Pengertian Pendidikan}

Sanjana (2006:2) menyatakan

bahwa pendidikan adalah

usaha sadar dan terencana

untuk mewujudkan suasana

belajar dan proses

pembelajaran yang efektif,

agar peserta didik secara aktif mengembangkan potensi dirinya untuk meningkatkan spiritualitas keagamaan agar semakin baik, kecerdasan yang selalu meningkat, akhlak mulia serta keterampilan yang diperlukan bagi dirinya, masyarakat , bangsa dan Negara. Sahertian (2000: 1) menyatakan bahwa pendidikan adalah usaha sadar yang dengan sengaja dirancang untuk mencapai tujuan yang telah ditetapkan.

\section{BIODATA PENULIS}

Selanjutnya dalam UU RI. No 20 tahun 2003 tentang sistem pendidikan nasional disebutkan bahwa pendidikan adalah usaha sadar dan terancam untuk mewujudkan suasana belajar dan proses pembelajaran agar peserta didik secara aktif menggembangkan potensi dirinya untuk memiliki kekuatan spiritual, keagamaan,

pengendalian diri,

kepribadian,kecerdasan,ahlak mulia, serta keterampilan yamg diperlukan dirinya, masyarakat bangsa dan negara. Purwanto (1998:10) menyebutkan bahwa pendidikan ialah usaha orang dewasa dalam pergaulannya dengan anak-anak untuk memimpin perkembangan
I Ketut Sudarsana lahir di

Desa Ulakan Kecamatan

Manggis Kabupaten

Karangasem Provinsi Bali

pada tanggal 4 September

1982. Ia adalah anak

bungsu dari tiga bersaudara

yang lahir dari pasangan I

Ketut Derani (Alm.) dan Ni

Ketut Merta. Menikah

dengan Adi Purnama Sari,

S.Pd.H. dan dikaruniai tiga orang anak; Saraswati Cetta

Sudarsana (4 tahun),

Kamaya Narendra

Sudarsana dan Ganaya

Rajendra Sudarsana (3

tahun). Pengalaman kerja

dimulai pada tanggal 1

Januari 2005 sampai

sekarang sebagai dosen

tetap IHDN Denpasar.

Email :

iketutsudarsana@ihdn.ac.id 
rohani dan jasmaninya kearah

kedewasaan, atau lebih

jelasnya lagi pendidikan

adalah pemimpin yang

diberikan secara sengaja oleh

orang dewasa kepada anak-

anak, dalam pertumbuhannya

(jasmani dan rohani) agar

berguna bagi diri sendiri dan

bagi masyarakat.

Hamalik (2004:3) memberikan

pengertian terhadap

pendidikan sebagai suatu

proses dalam rangka

mempengaruhi peserta didik

supaya mampu menyesuaikan

diri sebaik mungkin dengan

lingkunganya,dengan

demikian akan menimbulkan

perubahan dalam dirinya

yang memungkinkan untuk

berfungsi secara dekat dalam

kehidupan masyarakat.

Berdasarkan pendapat diatas,

maka dapat disimpulkan

bahwa pendidikan adalah

usaha sadar yang dilakukan

oleh orang yang memiliki

tanggung jawab atas pertumbuhan

dan

perkembangan seorang anak

agar nantinya dapat tumbuh

menjadi dewasa baik dalam

jasmani maupun rohaninya.

Dengan demikian orang-

orang yang dikatakan dewasa

dalam hal ini dapat dilihat dari

perkembangan jasmani dan

rohaninya yang seimbang

serta dapat mengambil suatu

kesimpulan terhadap

masalahnya sendiri, serta

dapat bertanggung jawab

terhadap beban hidup yang

di hadapi sebagai makhluk

sosial dalam masyarakat.

2. Pendidikan Agama Hindu

Pendidikan agama Hindu

adalah salah satu mata

pelajaran yang wajib

diterapkan di seluruh jenjang

dan jenis lembaga pendidikan

formal, baik negeri maupun

swasta, dari Taman Kanak-

kanak hingga Perguruan

Tinggi. Sama seperti halnya

dengan mata-mata pelajaran

yang lain. Pendidikan Agama senantiasa diarahkan untuk

mewujudkan Tujuan

Pendidikan Nasional, dan

pada akhirnya untuk

mewujudkan tujuan nasional

negara RI sebagaimana

tercantum pada alinea IV

Pembukaan UUD 1945 yaitu :

1) Mencerdaskan kehidupan bangsa,

2) Memajukan kesejahteraan umum,

3) Melindungi segenap bangsa Indonesia dan seluruh tumpah darah Indonesia,

4) Ikut melaksanakan ketertiban dunia berdasarkan perdamaian abadi dan keadilan sosial. Terkait dengan tujuan nasional di atas, pada Bab II Pasal 3 Undang-Undang Nomor 20 tahun 2003 dijelaskan bahwa :

Pendidikan nasional berfungsi mengembangkan kemampuan dan membentuk watak serta peradaban bangsa yang bermartabat dalam rangka mencerdaskan kehidupan bangsa, bertujuan untuk 
berkembangnya potensi siswa agar menjadi manusia yang beriman dan bertakwa kepada tuhan Yang Maha Esa, berakhlak mulia, sehat, berilmu, cakap, kreatif, mandiri dan menjadi warga negara yang demokratis dan bertanggungjawab (Lasmawan, 2006: 14)

Kompetensi Iulusan suatu jenjang pendidikan sesuai dengan tujuan pendidikan nasional mencakup komponen pengetahuan, keterampilan, kecakapan, kemandirian, kreativitas, kesehatan, akhlak, ketakwaan dan kewarganegaraan. Semua komponen pada tujuan pendidikan nasional harus tercermin pada kurikulum, sistem pembelajaran dan sistem penilaian.

Menurut peraturan pemerintah No. 19/ 2005 yang kemudian yang dituangkan lebih lanjut pada kurikulum tingkat satuan pendidikan, pendidikan agama Hindu termasuk ke dalam mata pelajaran akhlak

mulia dan kewarganegaraan.

Kelompok mata pelajaran ini dan kepribadian ini

dimaksudkan

untuk

meningkatkan kesadaran dan

wawasan peserta didik akan

status, hak dan kewajibannya

dalam kehidupan

bermasyarakat, berbangsa

dan bernegara serta

kehidupan beragama dan

kepercayaan terhadap Tuhan

Yang Maha Esa.

Terkait dengan eksistensi

pendidikan Agama Hindu

dalam kerangka kurikulum

tingkat satuan pendidikan

sebagaimana terurai di atas,

parisada Hindu Dharma

Indonesia pusat (1993:6)

menjelaskan bahwa

"pendidikan agama Hindu

pada dasarnya adalah

merupakan penunjang dalam

mencapai cita-cita

pembangunan dan tujuan

nasional

melalui pembangunan fisik dan

mental spiritual".

Sejalan dengan hal tersebut,

Departemen Pendidikan

Nasional dalam rumusan

standar kompetensi mata

pelajaran pendidikan Agama

Hindu untuk kurikulum 2004

memberikan pengertian

mengenai Pendidikan Agama

Hindu sebagai upaya sadar

dan terencana guna

menyiapkan peserta didik

mengenal, memahami,

menghayati, hingga

mengimani, bertakwa dan

berakhlak mulia dalam

mengamalkan ajaran agama Hindu dari sumber utamanya yaitu kitab suci Sruti, Smerti, Sila, Acara dan Atmanastuti. Pendidikan agama itu sendiri memiliki ruang lingkup untuk mewujudkan keserasian, keselarasan, dan kesinambungan hubungan dengan Tuhan, diri sendiri, sesama manusia dan makhluk 


\begin{tabular}{|c|c|c|}
\hline lain, maupun dengan & kepribadian umat Hindu yang & ranah pendidikan formal \\
\hline lingkungan (Tri Hita Karana). & baik, berbudi pekerti yang & dalam berbagai jenis dan \\
\hline Pendidikan agama & serta selalu & pendidikan \\
\hline pada dasarnya adalah salah & kehadapan Ida Sang Hyang & menurut kurikulum \\
\hline satu pendidikan penunjang & Widhi Wasa. & pendidikan \\
\hline dalam usaha mencapai cita- & Istilah pembelajaran pada & secara nasional di seluruh \\
\hline cita mental spiritual dan tujuan & konteks kekinian ditekankan & wilayah Indonesia tergolong \\
\hline pembangunan & pada bagaimana & ke dalam kelompok mata \\
\hline Pendidikan agama Hindu & mengajar dan bagaimana & pelajaran ahklak mulia dan \\
\hline melalui kebijakan Parisada & peserta didik mengajar Tirta & kewarganegaraan. \\
\hline Hindu Dharma Indonesia telah & (1990:42) menyatakan bahwa & \\
\hline menyusun berbagai program & pembelajaran adalah totalitas & 3. Karakteristik Pembelajaran \\
\hline Pendidikan Agama Hindu & keseluruhan kegiatan belajar & Pendidikan Agama Hindu \\
\hline dalam rangka pembinaan & mengajar dalam suatu proses & Praksita (1986:23) menyatakan \\
\hline umat Hindu. & transformasi nilai ide dan & agama \\
\hline Dengan demikian pendidikan & konsep dengan titik berat & petunjuk hidup yang berisi \\
\hline agama Hindu adalah suatu & pada bagaimana guna & sejumlah ide nilai dan norma \\
\hline upaya dalam rangka turut & mengajarkan sesuatu dan & yang seharusnya \\
\hline serta menyukseskan & bagaimana siswa belajar & pedoman dalam \\
\hline pembangunan & sesuatu. & berbicara dan bertingkah laku \\
\hline dalam bidang keagamaan & Berpijak & terwujudnya \\
\hline yang dilaksanakan secara & pengertian di atas jadi apa & keharmonisan umatnya dalam \\
\hline luas, terencana dan terus & yang dimaksud pembelajaran & dimensi \\
\hline menerus guna mengajak umat & pendidikan agama Hindu & keharmonisan \\
\hline Hindu untuk mempelajari, & sehubungan & manusia dengan \\
\hline memahami, menghayati, & penelitian tindakan kelas ini & hubungan manusia dengan \\
\hline mengamalkan & adalah keseluruhan proses & manusia \\
\hline agamanya sehingga dapat & kegiatan belajar mengajar & dengan lingkungan \\
\hline menumbuhkan sikap dan & pendidikan agama Hindu di & $\begin{array}{l}\text { Dalam konsep Hindu suasana } \\
\text { santi yang diwarnai oleh }\end{array}$ \\
\hline
\end{tabular}




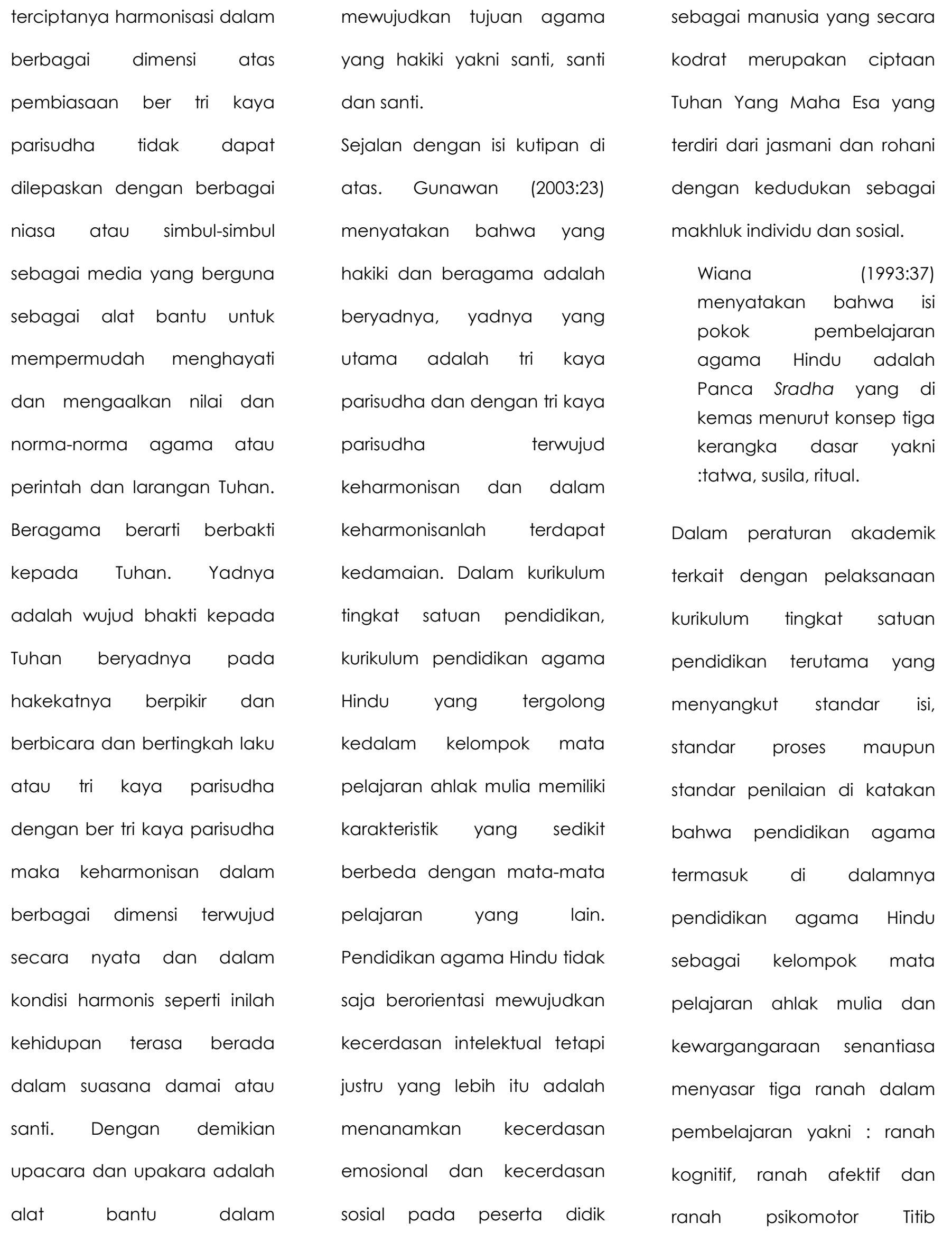


(2006:45) menyatakan bahwa

pendidikan budi pekerti memiliki kesamaan orientasi

dengan pendidikan agama

yakni mewujudkan sumber

daya manusia yang cerdas

dan terampil atas dasar ahlak

mulia yang kuat. Dengan

demikian pendidikan agama

dan pendidikan budi pekerti

sangat penting menumbuhkan

kemampuan siswa secara

intelektual tetapi jauh lebih

penting adalah mewujudkan

kemampuan peserta didik

dalam hal bersikap dan

bertingkah laku mulia sesuai

dengan norma-norma yang

ada ranah kognitif memang

penting, tetapi ranah afektif

dan ranah psikomotor lebih

penting.

Pendidikan agama Hindu

yang pada standar isinya lebih

menekankan afektif dan

psikomotor dari pada kognitif

domain berimplikasi pada

pengelolaan standar proses

dan standar penilaian pembelajaran. Berpijak pada

satandar isi yang ditetapkan

maka pada proses

pembelajaran pendidikan

agama Hindu senantiasa lebih

ditekankan pada proses

penginternasasisan sejumlah

komponen afektif dan

psikomotor di samping

komponen kognitif. Guru tidak

saja mengajarkan sejumlah

konsep kognitif tetapi juga

mendidik peserta didik untuk

mampu memiliki dan

menerapkan sejumlah konsep

afektif dan psikomotor.

Penilaian hasil belajar

pendidikan agama Hindu

tidak saja ditekankan pada

kemampuan siswa menguasai

sejumlah konsep kognitif tetapi

lebih difokuskan pada

kemavan dan kemampuan

peserta didik mengaplikasikan

konsep afektif dan psikomotor

secara nyata dalam

kehidupan sehari-hari dengan

demikian penilaian tidak

semata diarahkan pada kecerdasan, tetapi juga pada

sikap dan kepribadian peserta didik.

\section{Tujuan Pendidikan Agama}

\section{Hindu}

Pendidikan agama Hindu bertujuan untuk menumbuh kembangkan dan meningkatkan sradha (iman) dan bhakti (ketaqwaan) siswa terhadap Ida Sang Hyang Widhi Wasa melalui pelatihan, penghayatan dan pengalaman ajaran agama Hindu, sehingga menjadi insan Hindu yang dharmika dan mampu mewujudkan cita-cita luhur Moksartham Jagadita (Depdiknas, 2003 : 45).

Menurut Wiana (1997: 60-70) tujuan pendidikan agama Hindu adalah untuk membentuk manusia yang sudjana, susila dan subratha yang juga memiliki kepekaan sosial dalam arti yang luas. Tujuan pendidikan agama Hindu sesungguhnya sejalan dengan tujuan dalam ajaran 
agama Hindu, yakni untuk mewujudkan jagadhita dan moksa yang berlandaskan atas dharma.

Demikian juga dalam himpunan keputusan seminar kesatuan tafsir terhadap aspek-aspek agama hindu I XV (1999: 24) tujuan pendidikan agama Hindu adalah :

1. Membentuk manusia Pancasila yang astiti bhakti kepada Ida Sang Hyang Widhi Wasa/Tuhan Yang Maha Esa

2. Menanamkan ajaran Agama Hindu menjadi suatu keyakinan dan landasan segenap kegiatan umat dalam semua aspek kehidupan

3. Membentuk moral etika dan spiritual anak didik yang sesuai dengan ajaran-ajaran agama Hindu
4. Menyerasikan dan menyeimbangkan pelaksanaan bagianbagian ajaran agama Hinde dalam masyarakat antara tattwa, etika dan ritual Menurut peraturan Menteri Pendidikan Nasional Republik Indonesia nomor 22 tahun 2006 tentang Standar Isi untuk Satuan Pendidikan Dasar dan Menengah menyatakan bahwa tujuan pendidikan agama Hindu adalah untuk menumbuh kembangkan dan meningkatkan kualitas sradha dan bhakti peserta didik melalui pemberian, pemupukan, penghayatan, dan pengamalan ajaran agama serta membangun insan Hindu yang dapat mewujudkan nilai-nilai moksartham jagaditha dalam kehidupannya.

Dengan demikian dapat disimpulkan, bahwa tujuan pendidikan agama Hindu adalah

membentuk kepribadian sikap, mental dan budi pekerti dalam diri siswa. Agar siswa tersebut mampu memahami yang suputra, susila dan subiartha serta astiti bhakti dalam kehidupan sosial religius.

\section{Fungsi Pendidikan Agama}

\section{Hindu}

Pendidikan agama Hindu merupakan suatu proses penanaman dan pengajaran materi dan nilai-nilai ajaran agama Hindu. Dalam kehidupan manusia agama memiliki fungsi seperti yang dinyatakan oleh Cundamani (1993: 11-12) yaitu :

1. Agama memberikan pengetahuan tentang tujuan dan cara hidup. Laksana masuk di ruangan gelap orang menjadi takut karena terjadi sesuatu atau tidak tahu arah. Ketakutan itu timbul akibat ketidaktahuan 
atau kegelapan.

Agama dapat sebagai

obor yang menerangi

kehidupan sehingga

manusia bisa

menempuh jalan yang

benar dan bisa lebih

cepat menuju tujuan

hidup sejahtera baik

jasmani maupun

rohani

2. Agama memberi daya dorong untuk berbuat baik yang jauh lebih

memungkinkan

daripada orang yang

tidak beragama. Oleh

karena itu agama

tidak cukup diketahui

oleh umatnya lebih

dari itu perlu

diamalkan.

3. Agama dapat sebagai

obat dan peredam

dari gejolak batin

seseorang yang

dirundung kedukaan,

dengan agama orang

bisa menghibur dirinya sendiri kesedihan

sehingga mempunyai

daya tahan yang lebih

besar dari segala

macam penderitaan.

4. Agama memberikan

ketentraman hati dan

membebaskan orang

dari kecurigaan dan

ketakutan yang

berlarut-larut.

Terkait dengan fungsi agama

tersebut, Kurikulum Pendidikan

Agama Hindu (2004:2)

menjabarkan fungsi

pendidikan Agama Hindu

sebagai berikut :

1. penanaman nilai-nilai

ajaran Agama Hindu yang

dapat dijadikan Pedoman

hidup dalam mencapai

kesejahteraan

dan

kebahagiaan hidup

(moksartham jagadhita).

2. pengembangan

Sradha Dan Bhakti

Kehadapan Hyang Widhi

(Brahman)
3. pengajaran tentang ilmu pengetahuan keagamaan secara umum,system, dan fungsinya.

4. penyiapan

kemampuan sikap

mental siswa yang

ingin melanjutkan studi

ke jenjang yang lebih

tinggi.

5. mempersiapkan

kematangan dan

daya risistensi siswa

dalam mengadaptasi

diri terhadap

lingkungan fisik dan

sosial.

6. perbaikan kesalahan-

kesalahan,

kelemahan-

kelemahan peserta

didik dalam keyakinan

dan pengalaman

ajaran agama dalam

kehidipan sehari-hari.

7. pencegahan peserta

didik dari hal-hal

negative yang di 
akibatkan

oleh

pergaulan dunia luar.

Mengetahui fungsi dari

pendidikan Agama Hindu

maka akan lebih

mematangkan siswa dalam

mengahadapi diri terhadap

lingkungan fisik dan sosial juga

kemantapan akan keyakinan

tentang Pendidikan Agama

Hindu dalam kehidupan

sehari-hari.

\section{Pelaksanaan Pembelajaran}

\section{Pendidikan Agama Hindu}

Secara defacto dan the yure

pelaksanaan proses

pendidikan sebagai suatu

sistem bersandar pada tiga

komponen pokok yaitu

encironmental input, raw input

dan instrumental input. Dalam

proses pendidikan, output dan out come tercapai secara

maksimal apabila komponen

environmental input, raw input

dan instrumental input

bersenergi secara maksimal

pula.

Keberhasilan pelaksanaan

pembelajaran pendidikan

agama Hindu sangat

ditentukan oleh guru sebagai

komponen invoromental input

siswa sebagai raw input, dan

sarana prasarana fasilitas

sebagai komponen

instrumental in put dengan

demikian pelaksanaan

pembelajaran agama Hindu

segala kendala dan solusi

alternatif untuk mengatasi

kendala-kendala tersebut

senantiasa bersumber dan

diarahkan pada komponen guru siswa dan komponen

sarana pembelajaran.

Pelaksanaan pendidikan

pembelajaran agama Hindu

menjadi lebih bermakna dan

lebih efektif efisien apabila

seluruh komponen yang

berpengaruh di dalamnya

berada pada kompetensi

yang cukup memadai. Karena

itu agar pelaksanaan

pendidikan agama Hindu

berjalan secara ideal di

perlukan upaya maksimal

berupa pemberdayaan

secara ideal seluruh sumber

daya sekolah baik itu guru,

murid maupun sarana prasarananya.

Sugiharta, I. P. S. O., \& Sudarsana, I. K. (2017). Hypnotic Learning Characteristics On Sisya

Brahmakunta Community In Denpasar. Vidyottama Sanatana: International Journal of Hindu Science and Religious Studies, 1(2), 132-145.

Wisarja, I. K., \& Sudarsana, I. K. (2017). Praksis Pendidikan Menurut Habermas (Rekonstruksi

Teori Evolusi Sosial Melalui Proses Belajar Masyarakat). Indonesian Journal of Educational Research, 2(1), 18-26.

Wisarja, I. K., \& Sudarsana, I. K. (2017). REFLEKSI KRITIS IDEOLOGI PENDIDIKAN KONSERVATISME DAN LIBRALISME MENUJU PARADIGMA BARU PENDIDIKAN. Journal of Education Research and Evaluation, 1(4), 283-291. 